\title{
Truck routing cut and fill problem in roadworks using integer programming
}

\author{
Roteamento de caminhões usando programação inteira no problema de \\ corte e aterro em obras de terraplanagem \\ Viviane Adriano Falcão ${ }^{1}$, Ernesto Ferreira Nobre Júnior ${ }^{2}$, Bruno de Athayde Prata ${ }^{3}$ \\ ${ }^{1}$ Federal University of Pernambuco, Pernambuco - Brazil, viviane.afalcao@ufpe.br \\ ${ }^{2}$ Federal University of Ceará, Ceará - Brazil, nobre@ufc.br \\ 3Federal University of Ceará, Ceará - Brazil, baprata@ufc.br
}

\section{Recebido:}

24 de abril de 2019

Aceito para publicação:

14 de agosto de 2020

Publicado:

15 de dezembro de 2020

Editor de área:

Kamilla Vasconcelos

\section{Keywords:}

Earthmoving.

Vehicle Routing Problem.

Mathematical Programming

Palavras-chaves:

Terraplanagem.

Problema de roteamento de

veículos.

Programação matemática.

DOI:10.14295/transportes.v28i5.2032

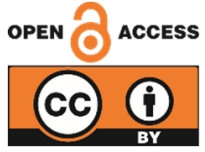

\begin{abstract}
Planning activities of materials distribution in earthworks may represent a gain in the work as a whole. One way to savings in the construction is to minimize the total distance travelled by equipment, for example the trucks between the cut and fill in earthmoving areas. Some studies have been reported on the optimization of material distribution between cut and fill areas, but only a few were applied in real projects considering multiple trucks, moreover they do not do any analysis based on the distance between stations. This paper aims at presenting an integer programming model that minimizes the distance travelled by dump trucks in distribution activities of earthwork materials. The developed model was based on a classical operational research problem named vehicle routing problem, which focus on the minimization of the travelled way by a fleet of vehicles. The proposed approach was applied in two case studies whose findings highlight significant gains, in terms of flexibility of the planning process. Engineers, planners and analysts have an important computational tool to support decision-making by using this model.
\end{abstract}

\begin{abstract}
RESUMO
Planejar as atividades de distribuição de materiais em obras de terraplenagem pode representar um ganho na obra como um todo. Uma das formas de fazer isso é minimizar a distância total percorrida pelos veículos, por exemplo caminhões na movimentação de terra entre as zonas de corte e aterro. Há muitos estudos e trabalhos que focam a otimização da distribuição de materiais entre zonas de corte e aterro, porém poucos aplicaram em projetos reais com a consideração de múltiplos equipamentos, além de não terem feito uma análise baseada na distância entre estacas. Este artigo tem como objetivo desenvolver um modelo de Programação Inteira que minimize a distância percorrida pelos caminhões basculantes em atividades de distribuição de materiais na terraplenagem. O modelo elaborado com princípios da Programação Linear Inteira foi baseado no problema de roteamento, cujo objetivo é minimizar o caminho percorrido. 0 modelo foi aplicado em dois estudo de casos cujos resultados destacam ganhos significativos, em termos de flexibilidade do processo de planejamento. Engenheiros, planejadores e analistas têm uma importante ferramenta computacional que facilitará a tomada de decisão.
\end{abstract}

\section{INTRODUCTION}

Highways are important to develop the economy in general; thus, it is through the flow of people and goods that the commerce can move. Roadwork is very complex because it involves activities with different stakeholders, staff, equipment and material.

In general, earthworks is an important activity in the total roadwork costs and in monetary value, it may represent more than a quarter of them according the work location (Hare et al, 
2011). Consequently, it is essential to achieve the best earthmoving costs for road planning and construction. Rashidi et al. (2014) stated that productivity estimation of the equipment is a significant challenge faced by many earthmoving contractors. Gwaka et al. (2018) confirm that an efficient earthworks plan reduces the total cost. It is important to define that the cost in this paper is related to monetary costs.

Henderson et al. (2003) stated that planners should develop a strategy to minimize the distance travelled by vehicles between the cutting and landfilling areas to achieve overall savings in construction. El-Rayes and Moselhi (2001) contended that resource optimization could lead to a significant reduction of the duration and cost of repetitive construction projects, such as roads, buildings, and housing development. Hwang et al. (2014) claim that the minimization of the earthmoving distance of the equipment must be included in the model to have an efficient earthwork planning.

There are many studies focused on mathematical optimization in earthmoving for roadworks (Falcão et al, 2016a), but a few of them have presented application in real-world projects, demonstrating that most of them are more interested only in the mathematical aspect, not in its applicability.

Another gap in the literature is the use of multiple equipment, as Henderson et al. (2003) highlighted as future studies. Moreover, it was not mentioned in the literature that if the distance between stations was used instead of the average distance of transport, the route could be optimized with this discretization.

Nassar and Hosny (2012) stated that the typical formulations of earthmoving problem, based on the transportation problem, do not consider the equipment movement sequence. Therefore, they are not able to establish a practical distribution plan and viable materials.

This paper aims at presenting an integer programming model for the optimization of truck routing in earthworks, considering the distribution of materials and a fleet of vehicles.

The proposed approach consists of a new mathematical model that incorporates multiple trucks and their route to the distribution activities of earthmoving materials in road works. It is also worth mentioning that the use of multiple trucks in optimization models is not available in the existing literature, considering that not even the model developed by Nassar and Hosny (2012) and Henderson et al. (2003), covers this alternative. Another contribution from this proposed model is to consider the discretized volume from fill or cut instead of Bruckner Diagram.

For the resolution of the integer programming models, the authors used the solver CPLEX. In addition, two case studies are presented and discussed, pointing to the robustness of the approach proposed.

\section{LITERATURE REVIEW}

Integer linear programming has been extensively employed in earthmoving modelling because of its simplicity and effectiveness. Normally, when integer linear programming is used, the analyst transforms the earthmoving problem into a transportation problem. In the transportation problem, the distances between the source (cut) and destination (fill) are predetermined, and the variables in the decision include the volumes that are transported. Then, the objective function can utilize two main approaches: minimizing direct monetary cost and minimizing distance. 
Kantorovitch (1958) may be considered the first to have studied and analysed the earthmoving (translocation mass) problem. This author presented a mathematical formulation in order to minimize the costs of earth displacements.

Mayer and Stark (1981) presented a method that was based on mixed integer programming to minimize earthmoving costs. The cost was the index for the decision variable (e.g., the volume transported), and they split earthwork costs into three parts: (1) excavation and loading, (2) transportation, and (3) placement and compaction. The transportation unit cost was considered proportional to the distance, but the authors did not consider the impact of soil type in the operations. Additional costs were considered when necessary, such as borrow pits. Regarding the distance, the authors considered the center of mass (e.g., average haul distance) and the setup cost for the borrow pit zone when necessary. The objective function was defined as the sum of the multiplication of unit costs by the decision variables, represented by the quantity of transported material (e.g., cut and fill areas, cut to disposal site, and cut to borrow pit).

Compared with Nandgaonkar (1981), Mayer and Stark (1981) incorporated more details in their analysis, such as shrinkage factors, borrow pits, disposal zones, different degrees of compaction, and different soil strata. The results of Mayer and Stark (1981) were comparable to the mass diagram and confirmed that mathematical programming can be applied in situations in which the mass diagram is unsuitable. Notably, the model of Mayer and Stark (1981) was not applied to a case study, which greatly limits the results of the model.

Easa (1987) proposed a model to optimize earthmoving operations by minimizing their total cost. Unlike previous models, this new model assumed that unit costs are not constant throughout the project. More specifically, this paper investigated the factors that affect variations in unit costs. Unit costs for purchases and excavation from borrow pits were considered variable in terms of amount, while other costs were assumed to be constant. This new model combined integer and linear programming and applied them to a numerical example that is considered an extension of the model of Mayer and Stark (1981).

Christian and Caldera (1988) also modelled earthmoving. They considered the shrinkage factor, transportation costs, compaction costs, and the need to use borrow pits or disposal areas. They applied linear programming to minimize the total cost of earthmoving. However, this study was criticized by Easa (1989) because Christian and Caldera (1988) considered only the areas of the borrow pit and disposal zones when there was no balance between the volumes of cut and fill areas. The second aspect criticized was the scheme in which the authors treated the cut and fill points, making it physically impossible to receive or dispose the material between them. They considered a high unit cost between these points to prevent the optimal solution passed by them.

Jayawardane and Harris (1990) developed a linear programming model that incorporated the work duration, soil strata, shrinkage factors, and equipment availability. The model sought to minimize earthwork costs in road construction by considering different alternatives to available equipment and thus provide material distribution and optimal equipment choices to complete the work in the required time. This was a complex problem, and the formulation became very long as the number of the sections of the road increased. The example presented by the authors only considered a fictional highway with six sections.

Jayawardane and Price (1994a) extended and improved the model that was developed by Jayawardane and Harris (1990). This model was applied in two case studies. 
In the first case study, a highway ( $8 \mathrm{~km}$ length), the costs could be reduced by approximately $20 \%$ using this model. The second case study was a fictional example that was used in previous works (Jayawardane and Price, 1994b). It can be concluded that the optimal solution would not be required to reduce the time to find the solution.

Hare et al. (2011) extended the classic models of mixed integer programming to minimize earthmoving costs in a road construction project. They considered the removal of physical barriers (e.g., rivers, trees, and rocks) that may considerably influence earthwork operations. They also included the option of borrow pits and disposal areas. The results provided significant savings for road projects. However, with the increasing number of road sections, the binary variables of the model increased, and the computation time made it impractical. Because of this, the second part of the paper introduced an algorithm that reduced the resolution time of the model. Lima et al. (2013) presented a mathematical model that related the geometrical and geotechnical characteristics of a road construction site to the allocation of materials, trying to find the minimum construction cost. A linear programming model was proposed to optimize earthmoving and roadwork. This model allowed the assessment of alternative sites with different soil layers and different degrees of compaction. Borrow pits were allocated in the most economical manner, and more inputs could be incorporated, such as the mix of materials. The proposed model showed that the cost of the work could be reduced through the rational allocation of materials.

Bogenberger et al. (2015) proposed a mathematical model to provide an optimal material distribution to complete the construction project in the specified time with minimum overall costs. Their model use concepts of linear programming. Yi and Lu (2016) developed an integer linear programming model for temporary haul road layout design in order to facilitate mass earthmoving operations.

In the route cut and fill problem (RCFP), the earthmoving problem is modelled as a vehicle routing problem. In this type of problem, the decision variables are the predetermined routes and distances between origin (cut) and destination (fill). Moreover, the objective function is to minimize the total distance travelled.

Henderson et al. (2003) presented a model based on the classic traveling salesman problem (TSP), in which a seller, from an initial city, needs to visit other cities once and return to the starting point, making the shortest path. Analogously, a given truck, departures from a cut, must complete the fills, and return to the cut. Decision variables are the arcs of the graph and the objective function is the total distance travelled.

In order to understand the modelling done by Henderson et al. (2003), it is necessary to know some definitions and hypothesis. In this model, it is considered that there is compensation between cut and fill, e.g. there is no need for disposal and borrow-pit areas. It was determined that the vehicle has a maximum capacity and that maximum load is taken on a trip (for example, a dump truck with a capacity of 20 cubic meters in each trip it will load 20 cubic meters). Another simplification of the problem is that the amount of cutting is equal to the number of fills.

Lim et al. (2005) developed a hybrid algorithm for the RCFP, based on the well known metaheuristics simulated annealing and tabu search. The authors tried to extend the model to include multiple vehicles, but a new mathematical formulation is not presented in the paper.

The shortest route cut and fill problem can be considered a special case of the least-cost route cut and fill problem developed by Nassar and Hosny (2012). The goal is to determine the route 
to be travelled and the amount of material that the construction equipment to carry to meet the desired grade, minimizing the total distance travelled.

Gwaka et al. (2018) formulate a computational method that determines the optimal sets of cut-fill pairs which identify the most economical EAP (earth allocation planning) considering the operational constraints. This model is based in the mixed integer linear programming (MILP) and evolutionary algorithm. It was applied in two cases studies as it results in a cost saving of 3.58\% of total earthmoving costs. Morais and Falcão (2019) validated the model constructed by Falcão et al. (2016b) and included the distance of transport to define the best equipment to be used in earthmoving.

\section{MATHEMATICAL FORMULATION}

The Truck Routing Cut and Fill Problem (TRCFP) is a combinatorial optimization problem in which the goal is to find a route that minimizes the total distance travelled by a fleet of trucks used in earthworks. Henderson et al. (2003) assume that minimizing the distance travelled, directly contributes to an overall economy of construction and reduces the displacements made by trucks and therefore the duration of the work as a whole.

Henderson et al. (2003) introduced a new variant of the vehicle routing problems called shortest route cut and fill problem (SRCFP). In this new variant, the objective function is to minimize the total distance travelled by a single earthmoving vehicle between cut and fill locations. Here, we extend the variant proposed by Henderson et al. (2003), taking into account the following innovative aspects:

a) In our proposal, a heterogeneous fleet of earthmoving vehicles is allowed. Since this assumption appears in the civil construction industry, we strongly believe that our proposal is suitable for the resolution of real-world problems.

b) Another innovative issue of the proposed variant is the consideration that the number of cuts does not need to be the same number of fills, as considered by Henderson et al. (2003). In our view, this assumption increases the robustness of the proposed modelling.

c) Another innovative assumption of the proposed approach is to consider a more realistic approximation of the distance between the cuts and fills, that is, the average distance between stations instead of the average haul distance between each cut or fill.

d) The number of visits for a given cut or fill depends on the volume of material required to conform it to grade-defined project. In the proposed approach, this volume is considered as load units. Since each material unit is a charging unit, the number of visits to each cut or fill area is equal the amount of excess (or deficit) of material. For example, if a given cut has a volume of $200 \mathrm{~m}^{3}$ to be removed and the truck capacity is $10 \mathrm{~m}^{3}$, this cut will be 20 units of the material to be removed.

As it follows, some notation is introduced for the TRCFP proposed model that is based on the shortest cut and fill problem. Let $\mathrm{D}$ be a matrix representing the Euclidean distances between cut and fill places.

For the definition of the mathematical model, we used the variables described below:

\section{Indices and sets:}

$A$ is the set of arcs from unit cut locations to unit fill locations where truck transports material;

$G$ is the set of cut and fill locations; 
$L+$ is the set of unit cut locations;

$L$ - is the set of unit fill locations;

$T$ is the set of trucks.

\section{Parameters:}

$p i$ is the position of unit cut or unit fill referring to li that is an element from sets L+e L-;

Dij euclidean distance matrix between cut i and fill j;

ci cut volumes vector;

fj fill volumes vector.

\section{Binary decision variables:}

[TRCFP]

$$
\begin{gathered}
x_{\mathrm{ijk}}=\left\{\begin{array}{c}
1, \quad \text { if the } k^{\text {th }} \text { truck transports material from cut } i \text { to fill } j \\
0, \quad \text { otherwise }
\end{array}\right. \\
y_{\mathrm{ik}}=\left\{\begin{array}{r}
1, \quad \text { if the } k^{\text {th }} \text { truck transports material from cut } i \\
0, \quad \text { otherwise }
\end{array}\right.
\end{gathered}
$$

Objective Function:

$$
\text { MinimizeZ }=\sum_{(i, j, k) \in A} D_{i j} x_{i j k}
$$

Subject to:

$$
\begin{gathered}
p_{i}+1-w\left(1-x_{i j k}\right) \leq p_{j} \forall(i, j, k) \in A, j \neq 1, p_{1}=1 \\
x_{i j k}+x_{j i k} \leq 1 \forall(i, j, k) \in A, i<j \\
x_{i j k} \in\{0,1\} \forall(i, j, k) \in A \\
p_{i} \in\{1, \ldots, l\}, i=1, \ldots, l \\
\sum_{j} x_{i j k}=y_{i k}, i=1, \ldots, m \wedge k=1, \ldots, t \\
\sum_{j} x_{i j k}=y_{j k}, j=1, \ldots, n \wedge k=1, \ldots, t \\
\sum_{k} y_{i k}=1, i=1, \ldots, n \\
\sum_{i, j} x_{i j k} \leq v, k=1, \ldots, t \\
x_{i j k} \in\{0,1\} \forall(i, j, k) \in A \wedge k=1, \ldots, t \\
y_{j k} \in\{0,1\} j=1, \ldots, n \wedge k=1, \ldots, t
\end{gathered}
$$

The objective function (1) minimizes the distance travelled by the fleet of truck moving material between cuts and fill areas. It is important to note that the presentation of the results could be converted in time, considering the productivity of a given fleet. The sets of constraints represented by (2) and (3) prevent the formation of subcircuits. Subcircuits are the formation of subgroups of cut or fill without having completed all the way. As a minimization model, it is necessary to include some restrictions to avoid that trucks do not stop their routes in the middle like the set restrictions (4) and (5). The set of constraint (6) is necessary to ensure that the truck does not visit a cut or fill more than once, that is valid because each cut and fill is discretized in a unit represented by the truck capacity. The set of constraints of type (7) balances the use of trucks, in which $\mathrm{v}$ is a parameter that regulates the amount of travels performed by a given truck. This balancing is flexible, allowing the analysis of various operational scenarios. Finally, the sets of constraints (8) and (9) are related to the binary nature of the decision variables. 


\section{CASE STUDIES}

Two case studies are presented, pointing to the robustness of the proposed approach. The case studies have different characteristics, DER SP (Roads Department of São Paulo State Brazil) and the project of a highway in the state of Pernambuco that was performed in 2009 as Studies and Projects of PE099.

It was used the software CPLEX 12.6, on an operating system Windows 8.1 64-bit, with Core i5 processor and $4 \mathrm{~GB}$ of RAM to optimize the problem.

\subsection{Case study 1 - DER São Paulo}

The volume to be transported from the cut area is about $1160.02 \mathrm{~m}^{3}$. The volume accumulated in the table and data from Brückner diagram will be used to compare the results.

$\mathrm{T}$ he distance covered by the trucks was of 3,938 meters, this distance was provided by the objective function. The CPLEX found this solution in around 6 (six) millisecond. The earthmoving was as shown in Table 1 . As the model has the constraint that requires balancing the trucks use (constraint set (7)), there is a balance in use, e.g. there were 28 trips to each truck.

Table 1 - Optimal distribution - case study 1

\begin{tabular}{cccc}
\hline \multirow{2}{*}{ Cut - Fill } & \multicolumn{3}{c}{ Earthmoving $\left(\mathbf{m}^{\mathbf{3}}\right)$} \\
\cline { 2 - 4 } & Truck 1 & Truck 2 & Total \\
\hline C-4 - F-1 & 40,0 & 100,0 & 140,0 \\
C4 - F2 & 80,0 & 40,0 & 120,0 \\
C5 - F2 & 320,0 & 220,0 & 540,0 \\
C5 - F3 & 120,0 & 200,0 & 320,0 \\
\hline
\end{tabular}

Figure 1 shows the time required for each truck to do earthmoving activities. This time was calculated by the average velocity equation, and this calculation was considered an average speed of $2 \mathrm{~m} / \mathrm{s}$. Each bar graph color represents the duration to carry between a cut and fill. For example, the green color illustrates the duration for the distribution of materials from cut 4 to fill 1, represented in label C4-F1.

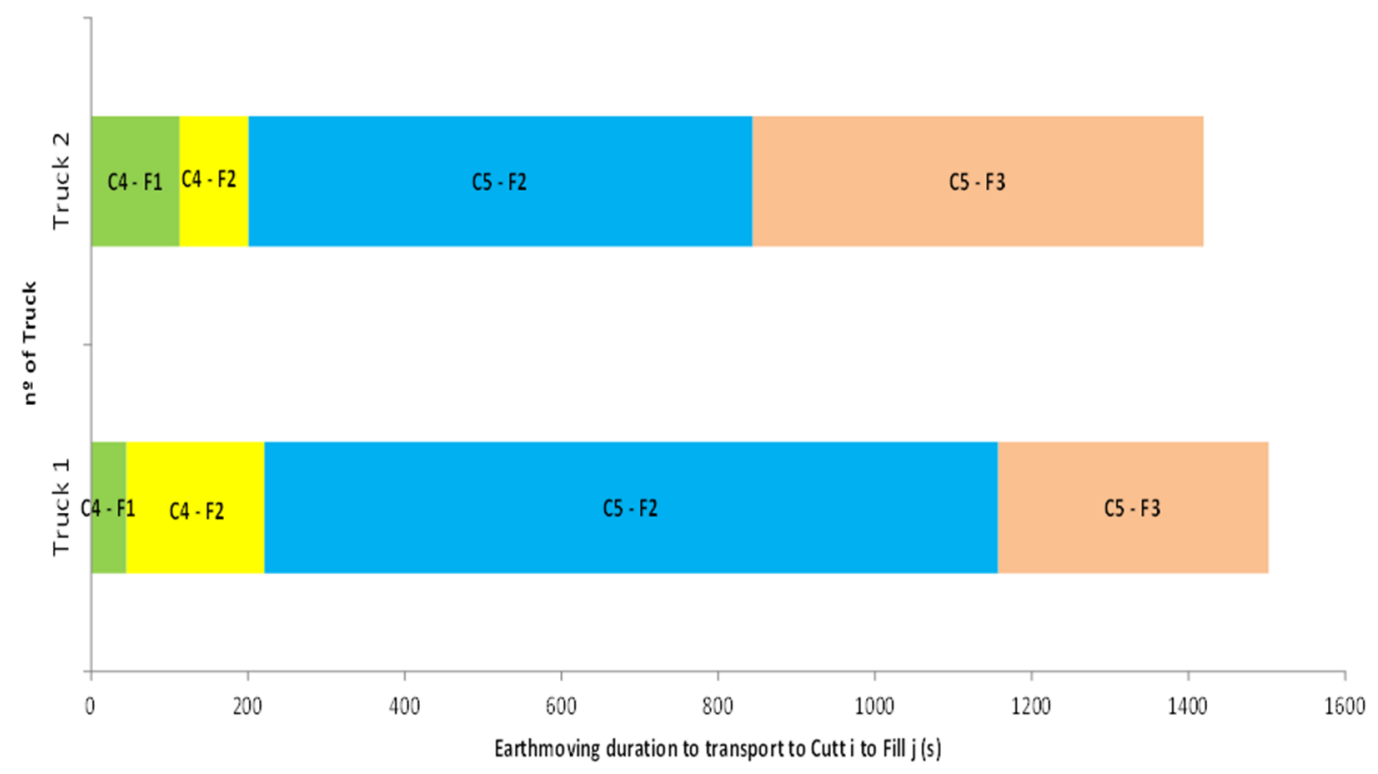

Figure 1. Earthmoving duration from cut to fill by trucks - DER SP. 
The optimal solution presented by the model was compared to the solution of the mass diagram, which is the haul of $79.32 \mathrm{~m}^{3} . \mathrm{km}$. The solution proposed by the model was $78.76 \mathrm{~m}^{3} . \mathrm{km}$ as shown in Table 2 . The solution generated resulted in a slight decrease of almost $1 \%$ of the distance travelled by the truck. It is believed that this decrease is minor because this problem has a small scale, where the manual solution is considered efficient. In any event, the model optimization focus is on the use and route of dump trucks, comparing with the Brückner diagram demonstrates that the movement of trucks influences the distribution of the materials.

Table 2 - Trucks Indicators - DER SP

\begin{tabular}{cccccc}
\hline & $\begin{array}{c}\text { Number } \\
\text { of trips }\end{array}$ & $\begin{array}{c}\text { Distance } \\
(\mathbf{k m})\end{array}$ & $\begin{array}{c}\text { Utilization } \\
\mathbf{( \% )}\end{array}$ & $\begin{array}{c}\text { Moved } \\
\text { Volume }\left(\mathbf{m}^{\mathbf{3}}\right)\end{array}$ & $\begin{array}{c}\text { Average haul distance } \mathbf{x} \\
\text { Volume } \mathbf{m o v e d}\left(\mathbf{m}^{\mathbf{3}} \cdot \mathbf{k m}\right)\end{array}$ \\
\cline { 2 - 6 } Truck 1 & 28 & 2.0 & 51.1 & 560 & 40.24 \\
Truck 2 & 28 & 1.9 & 48.9 & 560 & 38.52 \\
TOTAL & 56 & 3.9 & 100 & 1120 & 78.76 \\
\hline
\end{tabular}

After a thorough analysis of the results, it was realized that there could be an improvement in the solution provided by the model. It was hypothesized that it would be better to use the distance of each cutting unit volume for each unit volume of landfill. In this case, it was used the total average haul distance from cut sections to landfill sections, in other words, for each volume unit from cut 4, it was considered the average haul distance from the cut 4 to the fill 1.

The program was processed again, considering the circumstances described above. It was obtained the following results: the minimum distance travelled by the two trucks was 4,069 meters, somewhat larger than the distance obtained using the average haul distance, however, it can be considered as a value that best represents the reality.

A new processing was made considering the possibility of a disposal area. However, as there was no information about the distance of this section, the results obtained cannot be compared to the results of the example.

\subsection{Case study 2 - Highway PE099}

A case study is stated, pointing to the robustness of the proposed approach. The project is a highway built in the Northeast of Brazil, in the state of Pernambuco. Its project has a total length of about $32 \mathrm{~km}$ and it is an integral part of the final engineering design to Deployment, Paving and Road Restoration PE-099.

Given that on a road construction project of this size, the work is usually divided into sections for its implementation, the project PE099 was divided into smaller sections, which will be analyzed and processed separately. This division was not simply geometric; it was established based on production unit of the available equipment to execute the work. It is believed that the fact of splitting the case study in sections would not be a problem, since the actual planning of a road work is done that way, even to optimize the work fronts.

The next step is the division of the highway in stretches according to this production. Considering that the model unit load is a function of the loading capacity of the dump truck, the volume at each cut or fill will be divided by $14 \mathrm{~m}^{3}$. Other input data required by the model are the set distance between each cut and fill, the whole volume of cuts and the group of landfill volume. 
PE099 were divided in 5 sections, the beginning and ending stations of them, the actual volume (according to design) and the shaped volume. Each section was divided in 4 subsections. In the case of an integer linear programming-based model, it was necessary to round up some values. However, it will not interfere significantly in the result of the model, as it was of the order of less than $0.005 \%$, or $6 \mathrm{~m}^{3}$ in $120,742 \mathrm{~m}^{3}$.

As the volumes per station were obtained in the previous step and considering that, the model reads the volumes per charge unit, the volume of each station was divided by the dump truck capacity, $14 \mathrm{~m}^{3}$, as specified in the available list of equipment.

Thereafter, it was established the distance array between cut and fill from the data obtained on the earlier stage. The other required input data are the set distance between each cut and fill, the total volume of cuts, as well as volume of landfill. The distance between each cut and fill was defined as the average geometric distance between each cut and fill.

The PE099 was divided and represented by sections 1, 2, 3, 4 and 5, totalling around 120,736 $\mathrm{m}^{3}$ volume of earth to be moved in 86 cutting zones, 73 landfill zones and a disposal area with approximately $32 \mathrm{~km}$.

Figure 2 shows the required time for each truck to accomplish material distribution activities throughout the length of PE099, where each colour represents a stretch. To calculate the time, it was used the equation of the average speed, considering an average speed of $28.35 \mathrm{~km} / \mathrm{h}$. Truck 2 was slightly more used than the others, but in general the four trucks had a similar and balanced work time, and it took them on average 180 hours to complete the task. Note that this time is the truck trip time, regardless the back way neither the 8 hours of work, it means a continuous time and therefore fictitious.

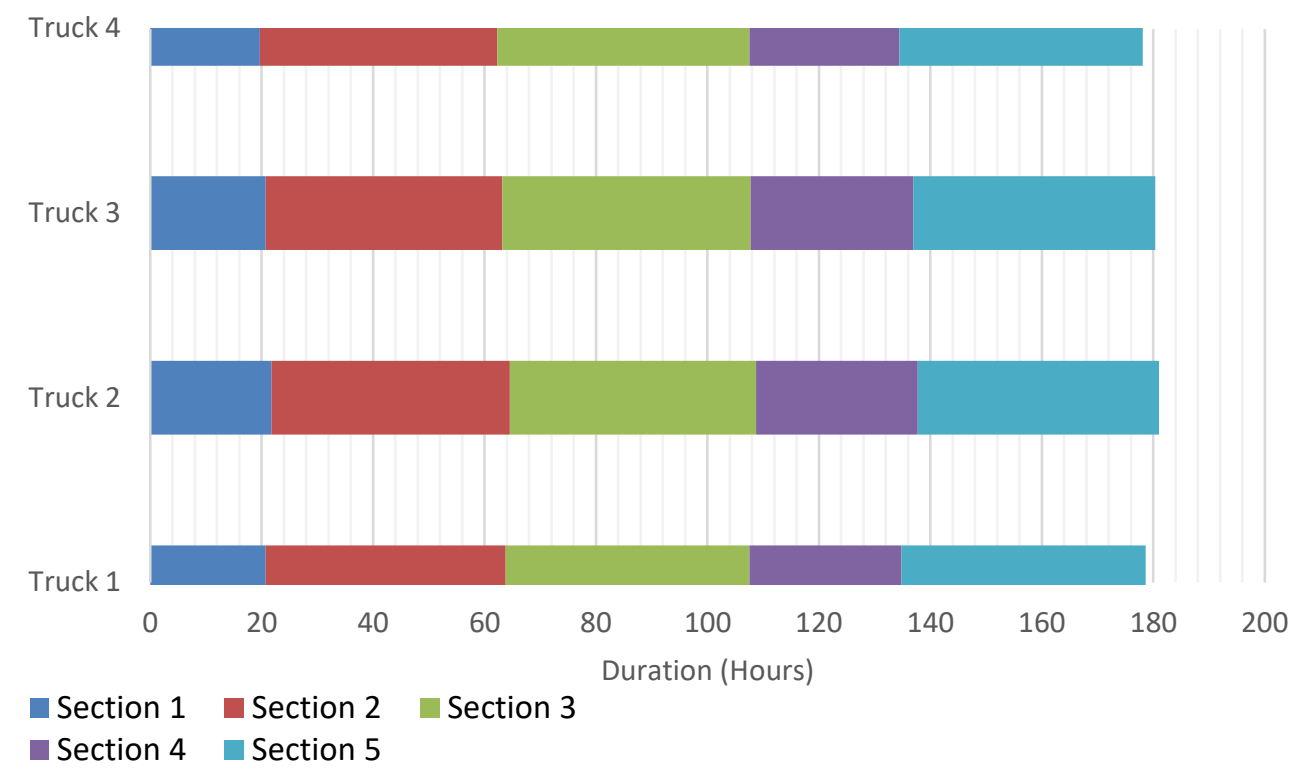

Figure 2. Duration to earthmoving from cut to fill by trucks - PE099

Table 3 shows the main statistics by truck over the entire length of PE099 - the distance travelled, the percentage of use, the volume moved and time of transport by truck are among them. As shown in Table 1, all trucks are operating with an average of $25 \%$ utilization, which means they are balanced, with a moved volume about $30,000 \mathrm{~m}^{3}$. 
Table 3 - Trucks Indicators - PE099.

\begin{tabular}{cccccc}
\hline & Number of Trips & Distance $(\mathbf{k m})$ & Utilization $\mathbf{( \% )}$ & Earthmoving $\left.\mathbf{( m}^{\mathbf{3}}\right)$ & Average distance $\mathbf{x}$ Earthmoving $\left(\mathbf{m}^{\mathbf{3}} \cdot \mathbf{k m}\right)$ \\
\hline Truck 1 & 2146 & $5,063.46$ & 25 & 30,044 & $70,888.44$ \\
Truck 2 & 2160 & $5,135.80$ & 25 & 30,240 & $71,901.20$ \\
Truck 3 & 2156 & $5,112.46$ & 25 & 30,184 & $71,574.44$ \\
Truck 4 & 2162 & $5,052.62$ & 25 & 30,268 & $70,736.68$ \\
\hline TOTAL & $\mathbf{8 6 2 4}$ & $\mathbf{2 0 , 3 6 4 . 3 4}$ & $\mathbf{1 0 0}$ & $\mathbf{1 2 0 , 7 3 6}$ & $\mathbf{2 8 5 , 1 0 0 . 7 6}$ \\
\hline
\end{tabular}

Figure 3 illustrates the use of each truck in two different situations with and without the balance constraint. Regarding Figure 3, it is possible to observe that the processed model without restriction (blue) has an overloaded use of the truck 1, since the haul for these trucks is greater than other hauls. With the balance restriction, it is perceived that there is a balance in the use of trucks.

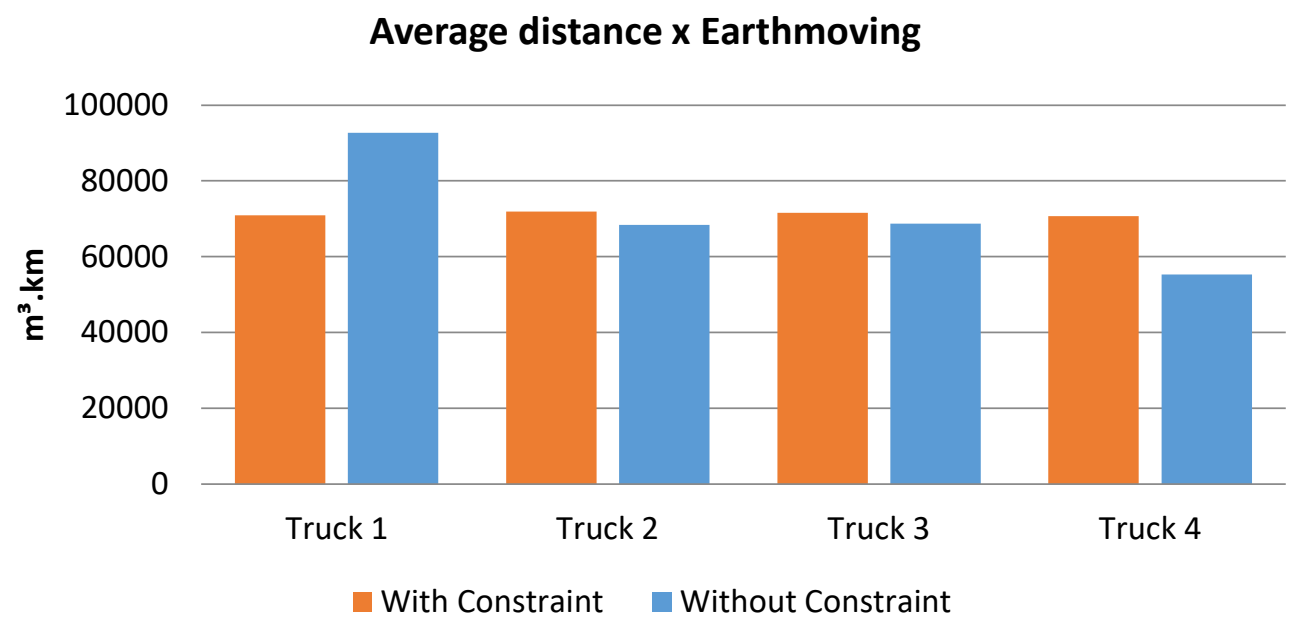

Figure 3. Average distance $x$ Earthmoving by trucks - PE099

Table 4 provides a summary of the main results of the PE099 model by sections and subsections. Column 4 (haul) shows the volume transported in each subsection multiplied by the distance covered in this subsection. Column 5 (distance) is the total distance travelled by trucks, provided the objective function.

The last two columns report the computational time spent by CPLEX for the model to find the optimal solution in each subsection. It is noteworthy that two scenarios were evaluated, one where a restriction of inequality was not considered (7), which aimed balancing the use of trucks, and the scene with this inequality. As expected, when the restriction was considered, the computational time to find the optimal solution increased. In addition, as the stretch increased its length and volume to be moved, a longer time was needed to find the optimal solution both in the case with, and in the case without, constraint. What is important to note is that when there is a balance constraint, the volume handled, and the section extension have a greater influence on the increasing in processing time.

According to the PE099 Project, the earthmoving planning was made through the mass diagram, which found a haul of $502,992.60 \mathrm{~m}^{3} . \mathrm{km}$, while the solution obtained by the model was $285,058.76 \mathrm{~m}^{3} \cdot \mathrm{km}$, as shown in the last two rows of Table 4 . Therefore, the solution generated by the model resulted in a decrease of about $43 \%$ of the time of transportation and decreasing 
the distance travelled by trucks, proving thereby the efficacy of the model above, especially with the increase of the length of the section studied. For information, if we consider the financial factor, when applying the model, we have a decrease of 986,415.26 real (Brazilian currency).

Table 4 - Summary of main results PE099 by subsections

\begin{tabular}{|c|c|c|c|c|c|c|}
\hline \multirow[b]{2}{*}{ Section } & \multirow[b]{2}{*}{ Volume $\left(\mathrm{m}^{3}\right)$} & \multirow[b]{2}{*}{ Subsection } & \multirow[b]{2}{*}{$\begin{array}{l}\text { Average distance } x \\
\text { Earthmoving } \\
\left(\mathrm{m}^{3} . \mathrm{Km}\right)\end{array}$} & \multirow[b]{2}{*}{$\begin{array}{c}\text { Distance } \\
(\mathbf{k m})\end{array}$} & \multicolumn{2}{|c|}{ Time for Solution - CPLEX } \\
\hline & & & & & $\begin{array}{c}\text { Without } \\
\text { Constraint } \\
\text { (mm:ss:ms) } \\
\end{array}$ & $\begin{array}{c}\text { With } \\
\text { Constraint } \\
\text { (mm:ss:ms) } \\
\end{array}$ \\
\hline \multirow{4}{*}{ TR-1 } & \multirow{4}{*}{24494} & TR-1A & 3686 & 263 & $23: 41: 92$ & $12: 20: 68$ \\
\hline & & TR-1B & 6536 & 467 & 04:36:32 & 01:14:95 \\
\hline & & TR-1C & 6245 & 446 & $31: 40: 24$ & $13: 26: 71$ \\
\hline & & TR-1D & 16416 & 1173 & $22: 23: 39$ & 12:18:34 \\
\hline & Total TR-1 & & 32883 & 2349 & - & - \\
\hline \multirow{4}{*}{ TR-2 } & \multirow{4}{*}{24449} & TR-2A & 19031 & 1359 & 14:33:64 & $12: 53: 35$ \\
\hline & & TR-2B & 9028 & 645 & 19:29:99 & 09:51:13 \\
\hline & & TR-2C & 14676 & 1048 & 13:18:17 & $07: 55: 35$ \\
\hline & & TR-2D & 25150 & 1799 & 18:05:79 & 11:39:08 \\
\hline & Total TR-2 & & 67885 & 4852 & - & - \\
\hline \multirow{4}{*}{ TR-3 } & \multirow{4}{*}{23998} & TR-3A & 29445 & 2103 & $27: 26: 32$ & $12: 19: 92$ \\
\hline & & TR-3B & 10700 & 764 & $24: 25: 29$ & 09:43:03 \\
\hline & & TR-3C & 16535 & 1181 & 13:28:62 & 05:57:79 \\
\hline & & TR-3D & 13863 & 990 & 11:07:83 & 07:09:70 \\
\hline & Total TR-3 & & 70543 & 5039 & - & - \\
\hline \multirow{4}{*}{ TR-4 } & \multirow{4}{*}{24527} & TR-4A & 12536 & 895 & 23:37:58 & $12: 33: 72$ \\
\hline & & TR-4B & 8882 & 634 & $20: 53: 37$ & $17: 30: 22$ \\
\hline & & TR-4C & 10358 & 740 & $34: 25: 25$ & $14: 45: 36$ \\
\hline & & TR-4D & 12828 & 916 & 04:30:24 & 01:59:10 \\
\hline & Total TR-4 & & 44604 & 3186 & - & - \\
\hline \multirow{4}{*}{ TR-5 } & \multirow{4}{*}{23275} & TR-5A & 19093 & 1364 & 20:51:83 & $11: 35: 26$ \\
\hline & & TR-5B & 22786 & 1628 & $16: 29: 93$ & 06:48:51 \\
\hline & & TR-5C & 19504 & 1393 & 19:25:95 & $11: 18: 54$ \\
\hline & & TR-5D & 7762 & 554 & $15: 29: 14$ & 08:55:78 \\
\hline & Total TR-5 & & 69144 & 4939 & - & - \\
\hline & Total PE099 - Model & & 285059 & 20364 & - & - \\
\hline & Total PE099 - Project & & 502993 & $-43,3 \%$ & - & - \\
\hline
\end{tabular}

\section{CONCLUSIONS}

The developed model was a variant based on a classic problem of Operational Research, the vehicle routing problem, in which the objective is to find the shortest route to pass through certain points. Mathematical programming was used, more precisely, the Integer Programming. It was also applied operational planning tools that are commonly used in the practical life of a great extension roadwork. The model aims to minimize the distance travelled by dump trucks in distribution activities of earthmoving materials in road works.

The Truck Routing Cut and Fill Problem - TRCFP can be considered a new variant of the Shortest Route Cut and Fill Problem. Besides, including trucks is a fact considered the model innovation, which is a differential because it promotes a balance in the use of trucks considering the distance between the stations, what means discretizing the problem.

The TRCFP was applied in two case studies demonstrating that the model can be applied for solving real-world problems. The case studies had different characteristics, one from the literature, DER SP and another a road project in the state of Pernambuco - PE099. 
Through the model, it can be made the operational planning of the route of trucks along the full extension of the material handling work, as well as the operational planning of the activities of dump trucks, in a way that can be created a work front weekly script of each truck.

In all sections of PE099, the proposed solutions for the model when compared with the planning solution showed a decrease, in addition, trucks had a balanced use and attended to the physical financial project schedule.

It is believed that, as the model considers the average distance between stations instead of the average haul distance, it has a more accurate analysis of the situation and therefore, a considerable reduction in haul as well as in the distance travelled by trucks. Also, it has an extremely effective allocation of distribution of materials. Another positive aspect of the model is the option to promote a balance in the use of dump trucks. Thus, it helps their rational use.

Regarding the computational time spent by the model to find the optimal solution, it has two different scenarios, one in which the restriction of balance in the use of trucks was not considered and another where it was considered. As expected, when the restriction was considered the computational time to find the optimal solution increased. It can also be concluded that as the stretch increased its length and volume to be moved, a longer time was needed to find the optimal solution either in case with, or without restriction. And in the scenario with some restriction, the volume handled and the passage of the extension have a greater influence in the increase in processing time.

In this context, automating the solutions generation in the planning process minimizes the time and effort spent, if compared to planning done manually. This can be demonstrated by the time it was necessary for the model to obtain the optimal solution for each of the stretches, on average 76 minutes for totaling about 6 hours to find the optimal solution the total length of PE099, for example.

Therefore, the study in question, is one of the fewest which uses integer Programming techniques and can apply their models in a real case study.

For future studies, it is suggested that the automation in obtaining the input data may be done by setting a pre-processor interface and a post-processor output interface with the printing of results. The possibility of a friendly interface with commercially available software could facilitate the use of the model by the decision makers.

Another research avenue is the extension of this model to a model that considers heterogeneous fleets, considering truck with other capabilities or even the possibility of considering the motorscraper in the situation where average haul distance is inefficient for dump trucks.

\section{ACKNOWLEDGEMENTS}

This study was financed in part by the Coordination for the Improvement of Higher Education Personnel (CAPES) - Finance Code 001, as well as the National Council for Scientific and Technological Development (CNPq), through Grant no. 303594/2018-7.

\section{REFERENCES}

Bogenberger, C.; Dell'amico, M.; Fuellerer, G.; Hoefinger, G.; Iori, M.; Novellani, S. and Panicucci, B. (2015) two-phase earthwork optimization model for highway construction. Journal of construction engineering and management. 2015, 141(6): 05015003. https://doi.org/10.1061/(asce)co.1943-7862.0000973

Christian, J. and Caldera, H. (1988). Earthmoving cost optimization by operational research. Canadian journal of civil engineering, 15:679-684. https://doi.org/10.1139/188-088

Easa, S. M. (1987). Earthwork Allocations with Nonconstant Unit Costs. Journal of construction engineering and management.113,34-50. https://doi.org/10.1061/(asce)0733-9364(1987)113:1(34)

Easa, S. M. (1989). Earthmoving Cost Optimization by Operational Research: Discussion. Canadian journal of civil engineering 16(3), 408. https://doi.org/10.1139/189-064 
El-Rayes, K. and Moselhi, O. (2001). Optimizing Resource Utilization For Repetitive Construction Projects. Journal of construction engineering and management, vol. 127, no. 1, January/February, 2001. https://doi.org/10.1061/(asce)07339364(2001)127:1(18)

Falcão, V. A.; Nobre Júnior, E. F. and Prata, B. de A. (2016a). Optimization Techniques Applied to Earthmoving and Highway Construction: A Survey. International Review of Civil Engineering (I.RE.C.E.), Vol. 7, N. 5 ISSN 2036 - 9913. September 2016. doi: 10.15866/irece.V7i5.10294.

Falcão, V. A.; Nobre Júnior and E. F. E Prata, B. de A. (2016b) Modelo de roteirização para a distribuição de materiais de terraplenagem baseado em programação inteira. Journal of transport literature. 10(3), 20-24. doi: 10.1590/22381031.jtl.v10n3a4

Gwaka, H.S.; Seob, J. and Leea, D.E. (2018) Optimal cut-fill pairing and sequencing method in earthwork operation. Automation in construction 87 (2018) 60-73. https://doi.org/10.1016/j.autcon.2017.12.010

Hare, L. W.; Koch, V. R. and Lucet, Y. (2011) models and algorithms to improve earthwork operations in road design using mixed integer linear programming. European journal of operational research, 215, 470-480. https://doi.org/10.1016/j.ejor.2011.06.011

Henderson, D.; Vaughan, D. E.; Jacobson, S. H.; Wakefield, R. R. and Sewell, E. C. (2003) Solving the Shortest Route Cut and Fill Problem Using Simulated Annealing. European journal of operational research 145 (2003) 72-84. Https://Doi.Org/10.1016/S0377-2217(02)00206-0

Hwang, S.; Son, J., and Lee, S. (2014) Development of Scheduling Model for Earth Work Using Genetic Algorithm. KSCE Journal of Civil Engineering (2014) 18(6):1618-1624.doi 10.1007/S12205-014-0398-1

IBM ILOG AMPL (2010) Version 12.2. User's Guidestandard (Command-Line). Version Including CPLEX Directives. May 2010. Available in: <http://ampl.com/booklets/amplcplex122userguide.pdf>. (Access in 30/10/2014).

Jayawardane, A. K. W. and Price, A. D. F. (1994a) A New Approach For Optimizing Earth Moving Operations, Part I, In: Proceedings of institution of civil engineers - transport, 105, Pp. 195-207. https://doi.org/10.1680/itran.1994.26795

Jayawardane, A. K. W. and Price, A. D. F (1994b) A New Approach For Optimizing Earth Moving Operations, Part Ii, In: Proceedings of institution of civil engineers - transport, 105, Pp. 249-258. https://doi.org/10.1680/itran.1994.27136

Jayawardane, A. K. W., and Harris, F. C. (1990) Further development of integer programming in earthwork optimization. Journal of construction engineering and management. 1990.116:18-34. https://doi.org/10.1061/(asce)07339364(1990)116:1(18)

Kantorovitch, L. (1958) On the translocation of masses. Management science vol. 5, no. 1 (oct., 1958), pp. 1-4. Https://www.jstor.org/stable/2626967

Lim, A; Rodrigues, B and Zhang, J. (2005) Tabu search embedded simulated annealing for the shortest route cut and fill problem. Journal of the operational research society (2005) 56, 816-824. doi:10.1057/palgrave.jors.2601900

Lima, R. X. de; Nobre Júnior, E. F.; Prata, B. de A. and Weissmann, J. (2013) Distribution of materials in road earthmoving and paving: a mathematical programming approach. Journal of construction engineering and management. 2013.139:10461054. Https://doi.org/10.1061/(asce)co.1943-7862.0000666

Mayer, R. H. and Stark, R. M. (1981) Earthmoving Logistics. Journal of the construction division, Vol. 107, No. 2, June 1981, pp. 297-312. https://cedb.asce.org/cedbsearch/record.jsp?dockey=0010248

Morais, B.A. and Falcão, V.A. (2019) Otimização de equipamentos em obras de terraplanagem utilizando programação linear inteira. Transportes. ISSN: 2237-1346. Volume 27. Número 4. 2019. doi:10.14295/transportes.v27i4.1814

Nandgaonkar, S. M. (1981) Earthwork transportation allocations: operations research. Journal of the construction division ASCE, vol.107, no. 2, 1981, pp 373-392. https://cedb.asce.org/cedbsearch/record.jsp?dockey=0010265

Nassar, K. and Hosny, O. (2012) Solving the least-cost route cut and fill sequencing problem using particle swarm. Journal of construction engineering and management, Vol. 138, No. 8, August 1, 2012. (CASCE, ISSN 0733-9364/2012/8-931-942. https://doi.org/10.1061/(asce)co.1943-7862.0000512

Rashidi, A., Rashidi Nejad, H. and Maghiar, M. (2014) Productivity estimation of bulldozers using generalized linear mixed models. KSCE journal of civil engineering (2014) 18(6):1580-1589. doi 10.1007/s12205-014-0354-0

Yi, C. and Lu, M (2016) A mixed-integer linear programming approach for temporary haul road design in rough-grading projects, Automation in construction (2016), http://dx.doi.org/10.1016/j.autcon.2016.08.022 